\title{
Changes in the Level of Mycorrhizal Colonization under Fertilization and Fungicide Treatment Conditions
}

\author{
Roxana VIDICAN, Vlad STOIAN*, Ioan ROTAR, Florin PĂCURAR \\ 1) Faculty of Agriculture. University of Agriculture and Veterinary Medicine Cluj, 3-5 Calea Mănăștur str., \\ 400372, Cluj-Napoca, Romania. \\ * corresponding author: vlad.stoian@usamvcluj.ro
}

Bulletin USAMV series Agriculture 71(2)/2014

Print ISSN 1843-5246; Electronic ISSN 1843-5386

DOI 10.15835/buasvmcn-agr: 10846

\begin{abstract}
Vesicular-arbuscular fungi have a major contribution to the absorption of nutrients from the soil using extraradicular hyphae networks and exploring the soil areas inaccessible to plant roots. Studies on the role and benefits of mycorrhizal symbiosis showed the major influence that they have on plant growth and development, as well as adjusting character for the internal processes from ecosystems. The objective of this paper was to examine the changes in the level of colonization produced by applying fungicides as base for grassland ecosystems balance conservation techniques under changes in the way of maintenance applied to these surfaces. To analyze the level of colonization were collected roots of Festuca rubra, in 2010-2011, from an experiment with 6 graduations of mineral and organic fertilization located in Garda de Sus village, on each variant being additionally applied a fungicide treatment. Frequency of colonization is high and more stable under the influence of fungicide treatment overlapped on fertilization with manure supplemented with nitrogen, while in conditions of NPK fertilization and combined with treatment this parameter is strongly reduced. In both sampling periods, mineral fertilization act to reduce the level of mycorrhizal colonization, responsible for this being the fungicide application over fertilization. Applying fungicides over organic fertilization can provide high levels of mycorrhizal colonization, aspect that can be used in plant conservation techniques for grassland ecosystems, in terms of changing the way of maintenance or further abandonment.
\end{abstract}

Keywords: mycorrhizal colonization, Festuca rubra, maintenance mode, conservation

Introduction. In natural ecosystems, vesicular-arbuscular fungi have a major contribution to the absorption and transfer of nutrients from soil to plants they colonize (Wu et al., 2013). For this purpose, in addition to the complex system of hyphae developed in soil for the absorption of nutrients, mycorrhizal fungi have also a strong intra-radicular expansion, facilitating the translocation of nutrients to the plant partner. Studies carried out so far have demonstrated the effectiveness of mycorrhizas for balancing the internal processes of ecosystems, having the ability to explore inaccessible areas and reducing losses and disturbances in the nutrients cycle (Liu et al., 2013).

Aims and objectives. The objective of this paper was to examine the changes in the level of colonization produced by applying fungicides as a base treatment for balance conservation techniques of grassland ecosystems, in the context of changes in applied management.

Materials and methods. To analyze the level of colonization were collected roots of Festuca rubra, in 2010-2011, from an experiment with mineral and organic fertilization located in Garda de Sus village, Romania, on each variant being additionally applied a fungicide treatment. Intraradicular colonization data (freq - Frequency $\%$, int - Intensity \%, cdeg - Colonisation degree \%) were colected at 100 days (maximum of period) and 150 (final of period) days from vegetation start. The experimental field consisted of six variants of fertilization $(\mathrm{F})$, graduation starting from control variant (F1 - unfertilized) and completed by two variants fertilized with $10 \mathrm{t} / \mathrm{ha}$ manure (F2) and $10 \mathrm{t} / \mathrm{ha}$ manure $+50 \mathrm{~kg} \mathrm{~N} 2$ (F3), and 3 variants 
Tab. 1. Differences in colonization parameters produced by overlapping treatment with a fungicide over the fertilization

\begin{tabular}{ccccccc}
\hline \multirow{2}{*}{ Fertilization } & \multicolumn{3}{c}{100 days } & \multicolumn{3}{c}{150 days } \\
\cline { 2 - 6 } & freq & int & cdeg & freq & int & cdeg \\
\hline F1 (control) & 82.78 & 18.92 & 17.06 & 92.22 & 22.59 & 20.92 \\
\hline F2 & $99.45^{*}$ & $29.26^{* * *}$ & $29.27^{* * *}$ & $63.89^{* * *}$ & $1.80^{* * *}$ & $1.23^{* * *}$ \\
\hline F3 & $98.33^{*}$ & $15.09^{\text {ns }}$ & $14.85^{\text {ns }}$ & $95.00^{\text {ns }}$ & $12.59^{* * *}$ & $11.97^{* * *}$ \\
\hline F4 & $56.11^{* * *}$ & $5.05^{* * *}$ & $3.33^{* * *}$ & $61.67^{* * *}$ & $1.96^{* * *}$ & $0.74^{* * *}$ \\
\hline F5 & $58.33^{* *}$ & $3.47^{* * *}$ & $2.24^{* * *}$ & $84.45^{\text {ns }}$ & $9^{* * 09^{* * *}}$ & $7.74^{* * *}$ \\
\hline F6 & $76.11^{\text {ns }}$ & $6.63^{* * *}$ & $5.06^{* * *}$ & $80.56^{*}$ & $2.85^{* * *}$ & $2.31^{* * *}$ \\
\hline
\end{tabular}

Note: Number of ${ }^{*}$ denote significant differences (LSD test, $\mathrm{p}<0.05, \mathrm{p}<0.01, \mathrm{p}<0.001$ ).

mineral fertilized with NPK 50:25:25 kg/ha (F4), Eurofertil mezocalc $120 \mathrm{~kg} / \mathrm{ha}+50 \mathrm{~kg} / \mathrm{ha} \mathrm{N} 2$ (F5) and F6 - Eurofertil mezocalc $120 \mathrm{~kg} / \mathrm{ha}$. The analysis of experimental data was performed with the software Statistica (Statsoft, 2012), LSD posthoc test.

Results and Discussion.By applying a fungicide treatment over the differentiated fertilization has created strong disturbances in both vegetation sequences. Compared to the control variant, the variants that had manure in the fertilizer recipe composition, recorded higher values of frequency and significant differences in the first growing vegetation sequence (Tab. $1)$. The same phenomenon also occurs in the second vegetation sequence, but only at the variant fertilized with manure supplemented with chemical nitrogen (F3). At each sequence of vegetation (Tab. 1), only a single variant of fertilization recorded intensity and colonization degree values higher than that observed at the unfertilized variant, respectively for the sequence of 100 days was the variant fertilized with manure (F2), and for the sequence of 150 days the variant that included manure and chemical nitrogen (F3) in the recipe. The recipes of mineral fertilization based on chemical nitrogen (F4 and F5), overlapped on a fungicide treatment, imprinted a strong reduction of colonization parameters, frequency falling below $60 \%$ in the first sequence of vegetation, and the degree of colonization was established below $5 \%$ (Tab. 1).
At the end of the vegetation period, the frequency of colonization is established around $60 \%$ of the roots and the degree of colonization under $2 \%$, for F2 and F4 variants, phenomenon due to the amount of NPK applied through fertilization and which amplified the effect of treatment with a fungicide. In the case of unfertilized variants, a fungicide treatments maintain colonization frequency to over $80 \%$ of the root system and the degree of colonization is stabilized at values between 17 and $20 \%$ during the entire vegetation period. This proves the effectiveness of applying fungicide treatments on areas where fertilizers are no longer applied, to maintain a high colonization level and a nutrient absorption area sufficient for the needs of the plant.

Conclusion.Applying fungicides over organic fertilization or on unfertilized areas can provide high levels of mycorrhizal colonization, aspect that can be used in conservation techniques for grassland ecosystems, in terms of changing the way of maintenance or further abandonment.

\section{REFERENCES}

1. Liu Y, Shi G, Mao L, Cheng G, Jiang S, Ma X, An L, Du G, Collins Johnson N, Feng H, (2012). Direct and indirect influences of $8 \mathrm{yr}$ of nitrogen and phosphorus fertilization on Glomeromycota in an alpine meadow ecosystem. New Phytologist, 194: 523-535.

2. STATSOFT, INC., 2012, Electronic Statistics Textbook. Tulsa, OK: StatSoft. WEB: http://www.statsoft.com/ textbook/.

3. Wu YH, Zhou J, Yu D, Sun S, Luo J, Bing H, Sun $H$ (2013). Phosphorus biogeochemical cycle research in mountainous ecosystem. J Mount Sci, 10: 43-53. 